\title{
Endometriosis of the Appendix
} Resulting in Perforated Appendicitis

\author{
Toru Hasegawa $^{\mathrm{a}}$ Koichi Yoshida ${ }^{\mathrm{b}}$ Kazuhiro Matsui \\ ${ }^{\text {aDepartment }}$ of Obstetrics and Gynecology, Faculty of Medicine, University of \\ Toyama, and Departments of ' Surgery and 'Pathology, Saiseikai Takaoka Hospital, \\ Toyama, Japan
}

\section{Key Words}

Endometriosis · Appendix $\cdot$ Perforated appendicitis

\begin{abstract}
Endometriosis is a relatively common disease among women of reproductive age. However, gastrointestinal endometriosis is rare and endometriosis of the appendix resulting in perforated appendicitis is even rarer. We experienced a case of endometriosis of the appendix manifesting as panperitonitis caused by perforation of the appendix. The patient was a 35-year-old woman who was hospitalized with an acute abdomen. She was diagnosed with panperitonitis and underwent urgent laparotomy. When perforation of the appendix was detected, appendectomy and intraperitoneal drainage were performed. Pathological examination revealed endometriosis extending from the muscularis propria to the subserosa, and a diagnosis of endometriosis of the appendix was made. We consider the relevant literature describing the mechanism by which endometriosis of the appendix occurs, and the association between endometriosis of the appendix and acute appendicitis.
\end{abstract}

\section{Introduction}

Endometriosis is a disease characterized by ectopic endometrial tissue, pathologically classified as benign proliferative changes. Approximately 1 of every 150 women will receive medical treatment for endometriosis, demonstrating that it is a relatively common disease among women of reproductive age. However, gastrointestinal endometriosis is rare, and endometriosis of the appendix presenting as acute appendicitis is even rarer [1]. We experienced a case of endometriosis of the appendix that presented as panperitonitis because of perforation of the appendix. We consider the mechanism by which endometriosis of the appendix occurs, and the relationship between endometriosis of the appendix and acute appendicitis, by reviewing the relevant literature. 


\begin{tabular}{c|l|l|l}
$\begin{array}{c}\text { CaseReportsin } \\
\text { Gastroenterology }\end{array}$ & $\begin{array}{l}\text { Case Rep Gastroenterol 2007;1:27-31 } \\
\text { Dol: } 10.1159 / 000104223\end{array}$ & Published online: June 22, 2007 & $\begin{array}{l}\text { @ 2007 S. Karger AG, Basel } \\
\text { ISSN 1662-0631 } \\
\text { www.karger.com/crg }\end{array}$ \\
\hline
\end{tabular}

\section{Case Report}

A 35-year-old nulliparous Japanese woman was admitted to hospital with a 3-day history of increasing lower abdominal pain. Her last menstrual period had been three weeks prior. Her menstrual cycle was regular and menstrual pain was mild. Her temperature at admission was $38.2^{\circ} \mathrm{C}$, and she complained of nausea. Localized tenderness and rebound tenderness were detected over the lower abdomen and were especially prominent in the right lower quadrant. Pelvic examination revealed that the uterus was of normal size and that there was localized mild tenderness, probably in either the right adnexal area or pouch of Douglas, but there was no adnexal mass. Endovaginal ultrasonography showed no apparent abnormality in the uterus or adnexa, but there was a relatively large amount of ascites within the pelvic cavity. Her WBC count was $12,500 / \mathrm{mm}^{3}$ with $94.6 \%$ neutrophils, and CRP was 10.1 $\mathrm{mg} / \mathrm{dl}$. Urinalysis was normal and her pregnancy test was negative. Computed tomography (CT) detected a large amount of right pelvic ascites and a calcified region in the right pelvic cavity (fig. 1). Tumor markers (CA125, CA19-9, CA72-4, AFP, CEA and SCC) were all negative. Because of the calcification in the pelvic cavity, we diagnosed panperitonitis resulting from either perforated appendicitis or a ruptured ovarian tumor such as a dermoid cyst, and chose to perform an emergency abdominal operation.

During the operation, we found coprolites and a large amount of yellow ascites within the pelvic cavity, but no abnormality of the uterus or adnexa. The appendix was markedly enlarged and adherent to the retroperitoneum. We performed appendectomy and drainage. The resected appendix was enlarged, measuring $6 \times 3 \times 2 \mathrm{~cm}$. Histology of the surgical specimen showed conspicuous edema and neutrophil invasion in the wall of the appendix. There were endometrial glands and stroma with partial hemorrhage extending from the muscularis propria to the subserosa, with inflammatory cell infiltration (fig. 2a). Histochemical staining showed that these stroma cells were estrogen-receptor and progesterone-receptor positive (fig. 2b), establishing a diagnosis of endometrial tissue. The pathological diagnosis was acute phlegmonous appendicitis associated with endometriosis.

After the operation, her fever resolved and hematologic inflammatory changes improved. She was discharged two weeks after the operation.

\section{Discussion}

Gastrointestinal tract endometrial lesions are found in $12 \%$ of patients with endometriosis, of which $85 \%$ are in the rectosigmoid region. Endometriosis of the appendix is uncommon, accounting for only $3 \%$ of cases with gastrointestinal endometriosis [2]. Examination of 1,496 appendectomy cases showed a frequency of endometriosis of the appendix of $0.80 \%[3]$.

Endometriosis of the appendix is asymptomatic, and is often found incidentally during operative treatment for pelvic endometriosis [3]. Almost all of the 12 cases reported by Uohara et al. were discovered incidentally during operation for endometriosis or uterine fibroids, and did not have symptoms of acute appendicitis [3]. Only one of the six cases reported by Langman et al. was symptomatic, with a preoperative diagnosis of acute appendicitis [4]. Mittal et al. reported slightly more cases, with 6 of 16 cases of endometriosis of the appendix presenting with acute appendicitis, 2 of whom had perforation of the appendix [5]. These reports indicate that endometriosis of the appendix resulting in preoperative symptoms of acute appendicitis is relatively uncommon, and that endometriosis of the appendix resulting in perforated appendicitis, as in this case, is very rare $[6,7]$.

The conventionally accepted opinion is that endometriosis of the appendix occurs as a direct extension of endometriosis of the right ovary, but this has become controversial 


\begin{tabular}{c|l|l|l}
$\begin{array}{c}\text { CaseReportsin } \\
\text { Gastroenterology }\end{array}$ & $\begin{array}{l}\text { Case Rep Gastroenterol 2007;1:27-31 } \\
\text { DOl: 10.1159/000104223 }\end{array}$ & Published online: June 22, 2007 & $\begin{array}{l}\text { @ 2007 S. Karger AG, Basel } \\
\text { ISSN 1662-0631 } \\
\text { www.karger.com/crg }\end{array}$ \\
\hline
\end{tabular}

since isolated endometriosis of the appendix without endometrial lesions of the genital tract or other locations has been reported [1]. Uohara et al. reported that 3 of 12 cases of endometriosis of the appendix were isolated, with the other cases having endometriosis of the ovary or other locations [3]. Langman et al. reported that three of six cases were isolated, and another had endometriosis of the right ovary and fallopian tube [4]. The present report is notable for its abdominal operation findings, which showed no endometriosis at any other site.

There is no currently accepted explanation for the occurrence of endometriosis at distant sites. Isolated endometriosis of the appendix cannot be accounted for by the implantation theory (menstrual blood flowing back through the fallopian tube into the abdominal cavity), but it may be accounted for by the metaplasia theory (undifferentiated coelomic epithelial cells remaining dormant on the peritoneal surface until the ovaries begin to function, after which they respond to cyclic hormonal stimulation in a similar manner to normal endometrial cells) or systemic metastasis (pieces of endometrial tissue embolizing through venous and lymphatic channels to distant sites such as the lungs or umbilical region) [8].

Histopathological examination of the appendix reveals a good correlation between the site and depth of appendiceal wall involvement, the presence of hemorrhage, and symptoms of acute appendicitis [5]. Mittal et al. reported that six patients with endometriosis of the appendix and acute appendicitis all had hemorrhage in the endometrial tissue, and no patient without hemorrhage had acute appendicitis [5]. Langman et al. reported similar findings [4]. Histopathological analysis revealed hemorrhage in the endometrial tissue in our case, suggesting that endometriosis of the appendix should be viewed as a cause of perforated appendicitis.

Endometriosis of the appendix is an interesting pathological condition. The mechanism by which it occurs is still not clear. We await further research regarding the possibility that endometriosis of the appendix can cause acute or perforated appendicitis. 


\begin{tabular}{c|l|l|l}
$\begin{array}{c}\text { Case Reportsin } \\
\text { Gastroenterology }\end{array}$ & $\begin{array}{l}\text { Case Rep Gastroenterol 2007;1:27-31 } \\
\text { Dol: 10.1159/000104223 }\end{array}$ & Published online: June 22, 2007 & $\begin{array}{l}\text { I 2007 S. Karger AG, Basel } \\
\text { ISSN 1662-0631 } \\
\text { www.karger.com/crg }\end{array}$ \\
\hline
\end{tabular}

Fig. 1. Computed tomography detected a large amount of right pelvic ascites (long arrow), the uterus (short arrow) (a), and a calcified region (arrow) in the right pelvic cavity (b).
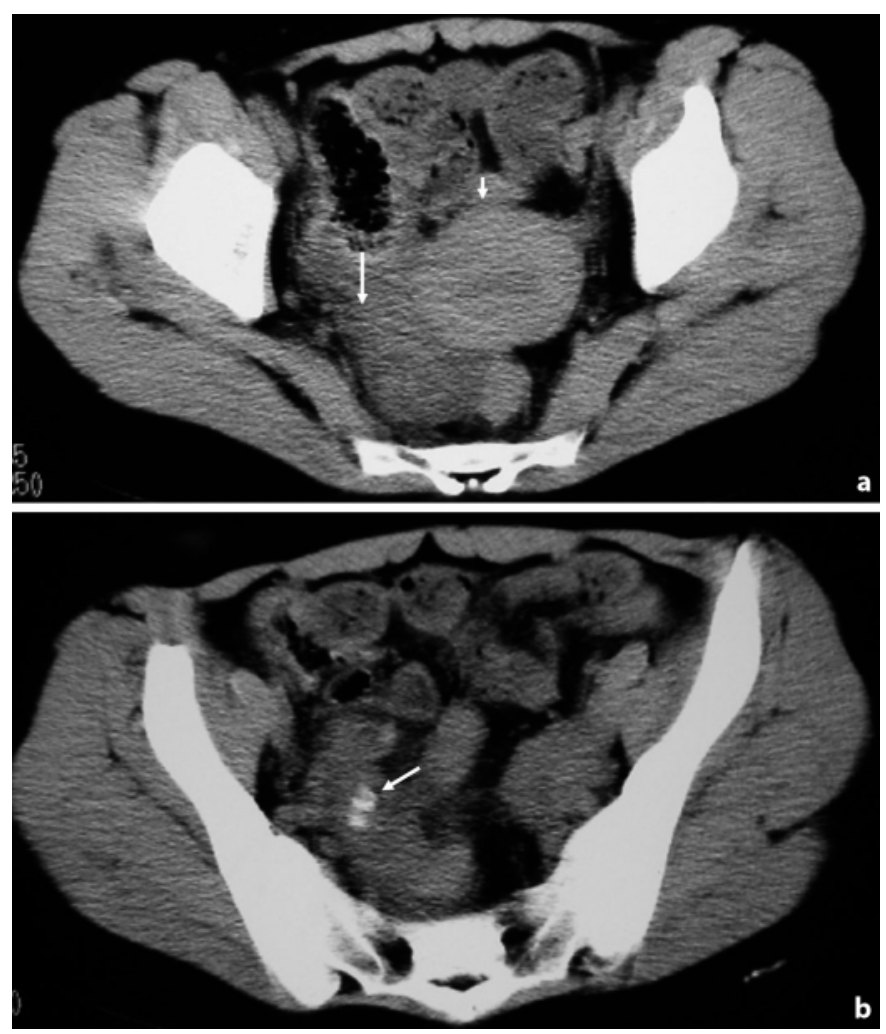

Fig. 2. Endometrial glands and stroma with partial hemorrhage extending in the muscularis propria (arrows) (a). Histochemical staining showed that these stroma cells were estrogen-receptor and progesterone-receptor positive (b).
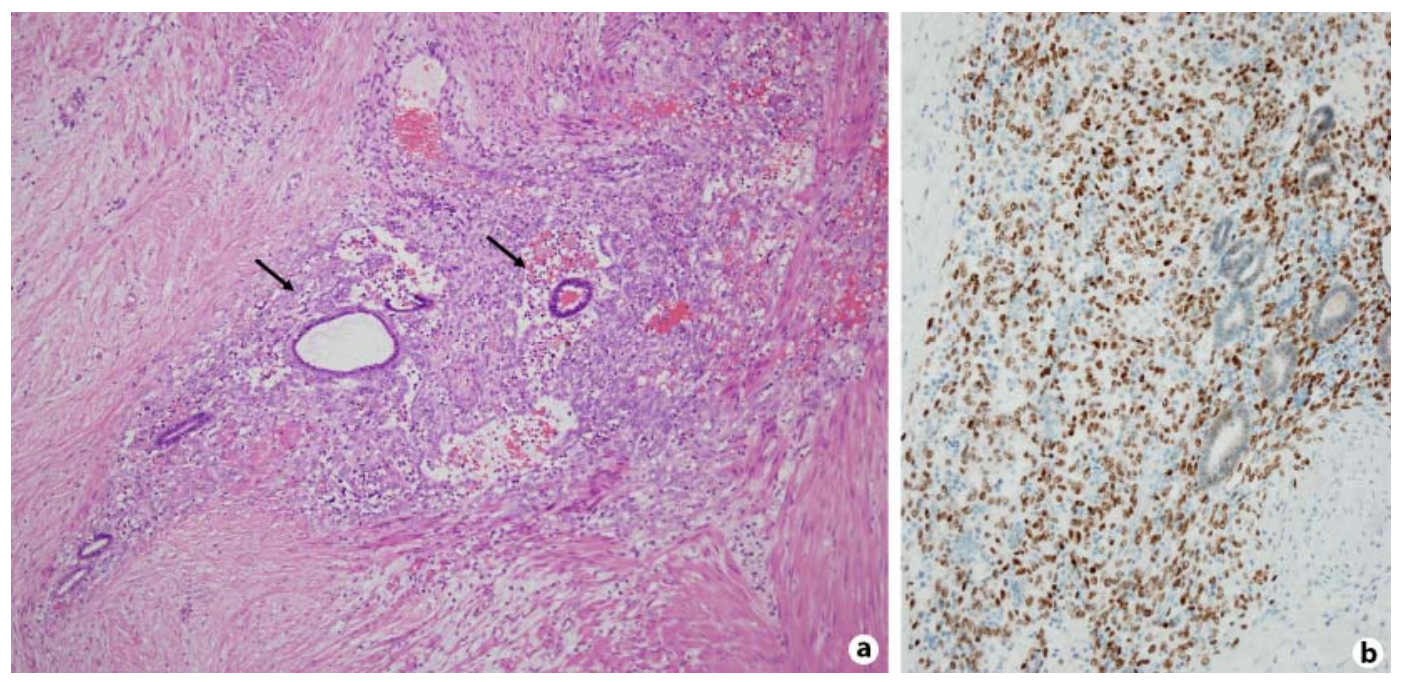


\section{References}

1 Khoo JJ, Ismail MSA, Tiu CC: Endometriosis of the appendix presenting as acute appendicitis. Singapore Med J 2004;45:435-436.

2 Haines JD Jr: Ileal endometriosis. Postgrad Med 1989;85:145-149.

3 Uohara JK, Kobara TY: Endometriosis of the appendix. Am J Obstet Gynecol 1975;121:423-426.

4 Langman J, Rowland R, Vernon-Roberts B: Endometriosis of the appendix. Br J Surg 1981;68:121-124.

5 Mittal VK, Choudhury SP, Cortez JA: Endometriosis of the appendix presenting as acute appendicitis. Am J Surg 1981;142:519-521.

6 Gini PC, Chukudebelu WO, Onuigbo WI: Perforation of the appendix during pregnancy: a rare complication of endometriosis. Br J Obstet Gynaecol 1981;88:456-458.

7 Nakatani Y, Hara M, Misugi K, Korehisa H: Appendiceal endometriosis in pregnancy. Report of a case with perforation and review of the literature. Acta Pathol Jpn 1987;37:1685-1690.

8 Cuzzo-Kriner MR: Intestinal endometriosis and its complications: Case report and review. Mt Sinai J Med 1989;56:334-337. 